\section{International Scientific Journal Theoretical \& Applied Science}

\author{
p-ISSN: 2308-4944 (print) e-ISSN: 2409-0085 (online) \\ Year: 2017 Issue: $06 \quad$ Volume: 50
}

Published: $30.06 .2017 \quad$ http://T-Science.org

SECTION 20. Medicine.
Irina Fedorovna Varban

Ph.D, Psychologist-psychotherapist, President of the Association of Psychologists and Psychotherapists of Moldova,

Teacher of the Slavic University

Chisinau, Moldova

Vladimir Igorevich Esaulov Institute of psychotherapy and clinical psychology Psychotherapy Department, Lecturer, Assistant, Department of Psychotherapy, Pirogov Russian National Research Medical University, Moscow, Russia v-esaulov@yandex.ru

\title{
PSYCHOTHERAPY OF PANIC ATTACKS
}

Abstract: Twenty patients were examined for the purpose of diagnosing panic attacks (PA). The initial examination was carried out with the help of clinical interviews and psychodiagnostic tests. All the examined patients showed somatic manifestations of PA, in combination with increased indices of personal and reactive anxiety. After interviewing and testing, patients were offered psychotherapeutic work with a psychologist, as well as training in relaxation techniques. The results of diagnosis and short-term psychotherapy can be useful for the therapy and prevention of panic anxiety conditions.

Key words: Anxiety, fear, panic attack, integrative psychotherapy, relaxation

Language: Russian

Citation: Varban IF, Esaulov VI (2017) PSYCHOTHERAPY OF PANIC ATTACKS. ISJ Theoretical \& Applied Science, 06 (50): 177-181.

Soi: http://s-o-i.org/1.1/TAS-06-50-26 Doi: croskef https://dx.doi.org/10.15863/TAS.2017.06.50.26

\section{ПСИХОТЕРАПИЯ ПАНИЧЕСКИХ АТАК}

Аннотация: Обследовано 20 пацчентов с ичелью диагностики у них проявлений приступов панических атак (ПА). Первичное обследование проводилось с помощью клинического интервью и психодиагностических тестов. У всех обследованных пациентов выявлены соматические проявления ПА, в сочетании с повышенными показателями личностной и реактивной тревожности. После опроса и тестирования пациентам была предложена психотерапевтическая работа с психологом, а такље обучение релаксационным приемам. Полученные результаты диагностики и краткосрочной психотерапии могут быть полезны для терапии и профилактики панических тревожных состояний

Ключевые слова: тревога, страх, паника, интегративная психотерапия, релаксация.

\section{Введение}

Современные условия жизни людей характеризуются повышением уровня напряжения в различных сферах жизни и способствуют увеличению количества лиц с различными невротическими расстройствами, среди которых значительный удельный вес имеют пациенты с паническими атаками [1-6]. Паническое расстройство введено в МКБ - 10 (код F41.0) и охватывает 4\% населения [6].

Паническая атака (ПА) - иррациональный, неуправляемый, интенсивный, истязающий приступ панической тревоги, сопровождающийся различными соматическими и психологическими симптомами, имеющий когнитивный и поведенческий эффекты [3,6-8].

В клинической практике приступы панических атак могут быть описаны также терминами: «вегетативный криз», «симпатоадреналовый криз», «вегетососудистая дистония с кризовым течением», «нейроциркуляторная дистония», «кардионевроз», что отражает тесную связь панических расстройств с сбоями в работе вегетативной нервной системы [8].

Из клинических наблюдений известно, что паническое расстройство обычно не ограничиваются однократным приступом паники. Испытанный первый эпизод мучительных ощущений откладывается в подсознании человека, что ведет к возникновению страха «ожидания» повторения приступа, и, в свою очередь, может спровоцировать возникновение новых панических атак. При этом многочисленные исследования не показывают 
какую-либо серьезную соматическую патологию $[3,7]$.

Виртуальный источник страха, который присутствует только в голове клиента, связан с внутренними переживаниями страдающих этим тревожно-фобическим расстройством, может вызывать крайне неприятные и тягостные телесные ощущения. Реакции вегетативной нервной системы готовят тело к энергичным действиям, к отражению надуманной опасности (по типу реакция "бей"/"беги"). В результате происходит увеличение частоты сердцебиений (тахикардия), более интенсивным становится дыхание (гипервентиляция), усиливается потоотделение, может появиться ознобоподобная дрожь, одышка, головокружение, повышение артериального давление и другие вегетативные проявления, сопровождающие страх $[3,7,8]$.

Схематически приступ панического страха можно представить в следующей последовательности:

Чувство внутреннего напряжения, дискомфорт $\rightarrow$ алогичный интенсивный страх $\rightarrow$ выброс адреналина в кровь $\rightarrow$ возникновение панической тревоги $\rightarrow$ еще большее производство надпочечниками и выброс адреналина $\rightarrow$ паническая атака [7-10].

Не смотря на многочисленные исследования, проясняющие характер возникновения панических атак, а также множество предлагаемых медикаментозных и психотерапевтических способов лечения ПА, до настоящего времени актуальным является поиск эффективных психотерапевтических способов совладания с этой пограничной психической патологией.

Целью данной работы явилось описание опыта краткосрочной амбулаторной психотерапевтической работы с клиентами с ПА, при которой основной задачей являлось обучение пациентов умению справляться с паническим расстройством для повышения качества их жизни и улучшения самочувствия.

\section{Материалы и методы}

Для исследования были выбраны 20 пациентов с ПА (12 женщин и 8 мужчин), обратившиеся за амбулаторной психологопсихотерпевтической помошью в психологический центр при Ассоциации Психологов и Психотерапевтов Республики Молдова (АППМ).

Возраст пациентов составлял от 17 до 44 лет. Среди обратившихся за помощью преобладали лица молодого возраста (до 30 лет), составившие более $2 / 3$ от общего числа пациентов с ПА.

Bce 20 человек прошли психологическое тестирование, включавшее Шкалу тревоги Шихана, Шкалу Цунга для самооценки тревоги, клиническое интервью, подтверждающее наличие тревожно- фобического расстройства, а также опросник на личностную и реактивную тревогу Спилбергера-Ханина, который давался в динамике на протяжении курса терапии.

На протяжении всего курса терапии - 5-6 недель - все 20 чел. проходили психотерапию 3 часа в неделю (3 встречи в неделю) и выполняли домашние задания по самонаблюдению и обучению релаксации.

В работе был использован интегративный подход с использованием когнитивноповеденческой и телесно-ориентированной терапии, арт-терапевтических техник, эриксоновского гипноза, а также ряда других психотерапевтических техник.

\section{Результаты и обсуждение}

В проведенном нами исследовании основное внимание направлялось на изучение интенсивности панического расстройства, а также составление схемы коррекции этого состояния, с проведением курса психотерапевтических занятий, направленных на уменьшение интенсивности (а в дальнейшем - и на исчезновение) выявленных тревожнофобических расстройств, что в итоге сказывалось на улучшении самочувствия и повышении качества жизни.

Полученные при первичном опросе жалобы и анамнестические сведения, а также данные анкетирования подтвердили наличие у клиентов психологических и соматических симптомов, типичных для панических расстройств невротического регистра.

Психологическое тестирование с использованием шкалы тревоги Шихана и шкалы Цунга для самооценки тревоги подтвердило наличие у испытуемых показателей, типичных для тревожно-фобических расстройств. Результаты тестирования опросником Спилбергера-Ханина указали на наличие у всех 20 человек повышенного уровня личностной и реактивной тревожности.

Всем 20 обследованным после психологического тестирования и опроса было предложено пройти индивидуальные сессии с психологом /психотерапевтом в режиме 3-х встреч в неделю в течение 5-6 недель. Помимо этого, пациентам давались домашние задания по самонаблюдению и закреплению навыков обучению релаксации. Общий курс занятий включал от 15 до 18 амбулаторных сессий продолжительностью от часа до полутора часов.

Проведенные сессии с психологом/психотерапевтом базировались на интегративном психотерапевтическом подходе. В каждом отдельном случае по показаниям (с учетом личностных особенностей пациентов и 
специфики психологических переживаний) использовались психотерапевтические техники, включающие различные элементы когнитивноповеденческой, телесно-ориентированной терапии и эриксоновского гипноза, арт-терапию, позитивную терапию, техники психомышечной релаксации и элементы аутотренинга [5,7,9,11-19]

Большая часть сессий содержала упражнения по уменьшению имеющегося напряжения и отреагированию эмоций, обучение релаксационным приемам с умением встраивать их в повседневную жизнь, работу со страхами, а также обучение умению переключаться с негативных переживаний на позитивные.

Естественно, что психотерапевтическая работа, начиная с первых сеансов, была возможна только после выстраивания комфортного и безопасного терапевтического пространства, с созданием и поддержкой эффективного рабочего альянса между психологом/психотерапевтом и пациентом с ПА, и постоянно поддерживаемой обратной связью.

Как уже отмечалось выше, в работе был использован интегративный подход с использованием когнитивно - поведенческой и телесно-ориентированной терапии, арттерапевтических техник. Фокус воздействия этих методик был направлен на осознание и коррекцию ограничивающих моделей мышления и поведенческих привычек, запускающий приступ паники.

При этом в отношении всех 20 пациентов с ПА был использован определенный поэтапный алгоритм психотерапевтической работы, включающий следующие стадии:

1. Вербализация переживаний при ПА. Первичный анализ имеющихся при ПА paccmpoйcmв. В начале психотерапевтической работы и в дальнейших сессиях нами активно поощрялось проговаривание пациентами своих переживаний. Вербализация переживаний могла способствовать частичному снижению напряжения, и помогала лучше осознавать своей личный вклад в возникновение и провоцирование приступов ПА.

2. Исследование когнитивной сферы пациентов с ПА. На этой стадии работы акцент делался на исследование когнитивных особенностей пациентов. Проводился анализ мыслей, которые присутствуют в повседневной жизни клиента, выявление негативных мыслей, особенно тех мыслей, которые запускают вегетативную реакцию.

1. Обучение распознаванию симптомов, характерных для разных этапов ПА. Эта стадия терапии способствовало лучшему пониманию последовательности возникновения ПА. Пациент обучался отслеживанию этапов развития панического приступа, отмечая те симптомы, которые появляются по ходу возникновения ПА.

2. Обучение распознаванию сигнального симптома ПА. Акцент работы здесь направлялся на выявление самого раннего симптома ("сигнального симптома"), который указывает на начало панической атаки.

3. Переключение внимания. На этой стадии пациенты осваивали навыки переключения внимания с негативных переживаний на позитивные.

4. Обучение релаксации. Пациенты с ПА осваивали различные релаксационные приемы, включающие управление мышечным тонусом, в сочетании с приемами регуляции дыхания. Проводилось обучение "седативному дыханию" с удлиненным выдохом.

\section{5. Встраивание}

релаксации в повседневную жизнь. На этой стадии терапии пациенты закрепляли полученные в ходе занятий умения, и систематически использовали релаксационные навыки при различных жизненных ситуациях.

\section{6. Включение навыков релаксации в схему} панического приступа. При регулярном использовании умений распознавать начало ПА и освоении релаксационных навыков становилось возможным управление своим самочувствием, и предотвращение развития приступов панических атак.

В процессе нашей работы у обследованных вырабатывалась и фиксировалась новая модель убеждений и поведения. При появлении панической тревожности купированию симптоматики ПА способствовали как полученные в ходе курса терапии релаксационные навыки, так и освоенные навыки регуляции самочувствия за счет самовнушения с помощью аутотренинга $[15,18,19]$.

Определенную роль в повышении внутренних ресурсов, уменьшении тревожности сыграли и применяемые в ходе терапии ресурсные эриксоновские трансы ("путешествие за ресурсом", "путешествие в мир покоя и комфорта", "старые и новые ресурсы"), а также рисуночные арт-техники (рисунки страха и состояния уверенности; "силуэт чувств"; триптихи я-обычный"/"я-впанике"/"япреодолевший страх"; "мое ресурсное состояние"; "мир гармонии и покоя"), и сеансы музыкотерапии.

Динамическое наблюдение в процессе терапевтической работы показало постепенное улучшение самочувствия у всех 20 человек с ПА, с урежением и исчезновением панических приступов. Субъективно у обследованных отмечалось уменьшение тревожности, постепенное освоение навыков управления своим самочувствием, укрепление уверенности в себе. 
Соматические симптомы в течение 5-6 недель терапии постепенно исчезли. Данные повторного психологического тестирования тестом Спилбергера-Ханина показало снижение уровня ситуативной тревожности.

Таким образом, спустя 5-6 недель после начала терапии отмечено снижение интенсивности/или исчезновение панического расстройства и улучшение качества жизни у всех 20 пациентов с ПА.

Для закрепления навыков управления своим самочувствием и поддержки полученных в ходе терапии умений саморегуляции пациентам было предложено продолжение посещения индивидуальных занятий с психологом в Центре АППМ в поддерживающем режиме (1-2 раза в месяц) в течение года с момента начала терапии. Более половины из обследованных (16 из 20 чел.) были настроены на продолжение занятий с психологом для продолжения работы по различным индивидуальным запросам, связанным в основном с темой личной успешности и уверенностью в себе.

\section{Заключение}

Успешная психотерапия лиц, страдающих паническими расстройствами невротического регистра может базироваться в первую очередь на использовании интегративного подхода с учетом личных особенностей пациентов и особенностей проявления симптоматики ПА.

При появлении панической тревожности отмечена целесообразность оказания психологопсихотерапевтической помощи, направленной на купирование имеющейся симптоматики и обучение специальным релаксационным и ресурсным приемам.

Полученные в ходе данного исследования результаты могут быть полезны при разработке психокоррекционных программ в работе с пациентами с тревожными паническими состояниями.

\section{References:}

1. Francesetti G (2007) Panic attacks and postmodernity. Geshtalt therapy between clinical and social perspectives. / Insituto di gestalt H.C.C., Italy. FrancoAngeli., 2007. $264 \mathrm{p}$.

2. Frenkel' YA (2010) Psihologiya straha. - M.; Profit Staj1, 2010. - 272 p.

3. (2015) Klinicheskie rekomendacii po diagnostike i lecheniyu panicheskogo rasstrojstva i generalizovannogo trevozhnogo rasstrojstva. Proekt. - M., Rossijskoe obshchestvo psihiatrov. 2015. - 49 p.

4. (2008) Klinicheskoe rukovodstvo po psihicheskim rasstrojstvam / pod red. D.Barlou.- SPb.: Piter, 2008. pp.18-102.

5. Nardone G (2008) "Strah, panika, fobiya: Kratkosrochnaya terapiya" (Per.s angl.) - M.: Psihoterapiya, 2008. - 352 p.

6. (2017) Mezhdunarodnaya klassifikaciya boleznej 10-go peresmotra (MKB-10) Elektronnyj spravochnik MKB-10. 1990-2017. Kody diagnozov, poisk po kodu i nazvaniyu bolezni. Available: http://www.mkb10.su/ (Accessed: 26.06.17)

7. Holmogorova AB, Dovzhenko TV, Garanyan NG (2017) Chto takoe panicheskoe rasstrojstvo i kak ego lechit'. Posobie dlya pacientov. -M.: Moskovskoe NII psihiatrii MZ RF. Available:
http://psihoterapijadljavseh.ru/pluginAppObj_3 740/panika_posobie.pdf (Accessed: 26.06.17)

8. (2000) Vegetativnye rasstrojstva: Klinika, lechenie, diagnostika. / Pod red. A. M. Vejna. - M.: Medicinskoe informacionnoe agentstvo, 2000. - 752 p.

9. Kovpak DV (2007) Kak izbavit'sya ot trevogi i straha. Prakticheskoe rukovodstvo psihoterapevta - SPb.:, Nauka i tekhnika. 2007.$240 \mathrm{p}$.

10. (2012) Rannyaya diagnostika trevozhnofobicheskih rasstrojstv $\mathrm{u}$ podrostkov $\mathrm{v}$ obshchemedicinskoj praktike. Metodicheskie rekomendacii - SPb.:, Izd. centr NIPNI im.VM.Bekhtereva. - 2012.-23 p.

11. Ginsburg MR, Yakovleva EL (2015) Eriksonovskij gipnoz: Sistematicheskij kurs. M.; Nezavisimaya firma "Klass". 2015.- 264 p.

12. Goloshchapov A (2016) Trevoga, strah i panicheskie ataki. Kniga samopomoshchi. M.:IG «Ves'», 2016. - 130 p.

13. Gordeev MN (2015) Fundamental'noe rukovodstvo po eriksonovskomu gipnozu. M.; Psihoterapiya.- 2015.- 357 p.

14. Kiseleva MI, Kulganov VA (2014) Art-terapiya $\mathrm{v}$ psihologicheskom konsul'tirovanii. Uchebnoe posobie. SPb.: Rech', 2014. - 64 p.

15. Krejz R (2002) Relaksaciya (Per.s angl.) - M.: Fair-press..- 256 p. 


\begin{tabular}{l|lrl|l|ll} 
& ISRA (India) & $=\mathbf{1 . 3 4 4}$ & SIS (USA) & $=\mathbf{0 . 9 1 2}$ & ICV (Poland) & $=\mathbf{6 . 6 3 0}$ \\
Impact Factor: & ISI (Dubai, UAE) $=\mathbf{0 . 8 2 9}$ & PUHL (Russia) $=\mathbf{0 . 2 3 4}$ & PIF (India) & $=\mathbf{1 . 9 4 0}$ \\
& GIF (Australia) & $\mathbf{0 . 5 6 4}$ & ESJI (KZ) & $=3.860$ & IBI (India) & $=\mathbf{4 . 2 6 0}$ \\
& JIF & $\mathbf{1 . 5 0 0}$ & SJIF (Morocco) & $=\mathbf{2 . 0 3 1}$ & & \\
\hline
\end{tabular}

16. Prashko YA, Mozhny P, Shlepecki M, et al. (2015) Kognitivno-bihevioral'naya terapiya psihicheskih rasstrojstv. - M.: Institut obshchegumanitarnyh issledovanij, - $1072 \mathrm{p}$.

17. (2000) Rukovodstvo po telesno-orientirovannoj terapii. - SPb.: Rech', - 256 p.
18. Shojfet MS (2010) Psihofizicheskaya samoregulyaciya. Bol'shoj sovremennyj praktikum. - M.: Veche, - 678 p.

19. Shul'c IG (1985) Autogennaya trenirovka / (per. s nem.) - M. : Medicina, - 32 p. 


\begin{tabular}{l|lr|ll|ll} 
& ISRA (India) & $\mathbf{1 . 3 4 4}$ & SIS (USA) & $=\mathbf{0 . 9 1 2}$ & ICV (Poland) & $=\mathbf{6 . 6 3 0}$ \\
Impact Factor: & ISI (Dubai, UAE) $=\mathbf{0 . 8 2 9}$ & PUHЦ (Russia) & $=\mathbf{0 . 2 3 4}$ & PIF (India) & $=\mathbf{1 . 9 4 0}$ \\
& GIF (Australia) & $=\mathbf{0 . 5 6 4}$ & ESJI (KZ) & $=\mathbf{3 . 8 6 0}$ & IBI (India) & $=\mathbf{4 . 2 6 0}$ \\
& JIF & $\mathbf{1 . 5 0 0}$ & SJIF (Morocco) & $\mathbf{2 . 0 3 1}$ & & \\
\hline
\end{tabular}

